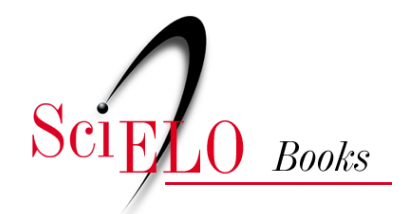

\title{
EDUFU
}

\section{Sobre a voz em sua função poética}

\author{
Sara Lopes
}

\section{SciELO Books / SciELO Livros / SciELO Libros}

Lopes, s. Sobre a voz em sua função poética. In: FLORENTINO, A., and TELLES, N., eds. Cartografias do ensino do teatro [online]. Uberlândia: EDUFU, 2008, pp. 271-282. ISBN 978-857078-518-3. https://doi.org/10.7476/9788570785183.0027.

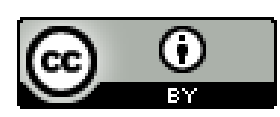

All the contents of this work, except where otherwise noted, is licensed under a Creative Commons Attribution 4.0 International license.

Todo o conteúdo deste trabalho, exceto quando houver ressalva, é publicado sob a licença Creative Commons Atribição 4.0.

Todo el contenido de esta obra, excepto donde se indique lo contrario, está bajo licencia de la licencia $\underline{\text { Creative Commons }}$ $\underline{\text { Reconocimento 4.0. }}$. 


\section{SOBRE A VOZ EM SUA FUNÇÃO POÉTICA}

Sara Lopes

\section{Um conceito, uma função...}

A compreensão do papel da voz como objeto da arte faz pressentir a existência de um plano mais profundo em suas funções e características, quando utilizada como material da linguagem de representação. Esse nível de comunicação oral, do qual emerge a função poética da vocalidade, constrói seu significado entre a materialidade das vibrações sonoras de uma voz e a sonoridade - melódica e rítmica - de uma fala. Entenda-se, por vocalidade, o uso imediato de uma voz que pede por uma expressão que somente se concretiza na co-presença intérprete/espectador: ela só se realiza no encontro entre aquilo que o intérprete exterioriza com o interior do ouvinte.

Por poética, como adjetivo, fica denominada a função que tem uma voz de ir além de seu uso utilitário na linguagem, da transmissão de idéias ligadas ao significado das palavras, criando o gesto vocal, gerando impressões, dizendo de si mesma e se comentando enquanto comenta e diz, mantendo o movimento interno ao procedimento técnico que leva à expressão diferenciada.

É pela vocalidade poética que os signos se tornam coisas. Porque as palavras não são as coisas; são representações convencionadas, abstrações. A coisa da palavra falada são as formas dos sons. No exercício da vocalidade poética, o revestimento constituído por um texto se rompe e, pelas aberturas, um outro discurso é proposto. Um discurso que, de maneira específica, marcada e diferente a cada tempo e lugar, transgride os esquemas discursivos comuns: nas vibrações de uma voz se desenrola um fio que liga, às palavras, os sinais vindos da experiência. $O$ que permanece, como força referencial, põe em destaque o contato entre os sujeitos corporalmente presentes: o que tem a voz e o que a recebe. Os valores que a vocalidade poética torna relevantes fundamentam-se sobre as qualidades da voz, sobre a técnica vocal do ator ou cantor, tanto ou mais que sobre o conteúdo da mensagem. Ela faz emergir, da linguagem, tudo o que não serve à informação, tudo o que define a situação de comunicação.

Os pressupostos da vocalidade poética enraízam-se e extraem sua validade da tradição oral, na qual toda palavra se liga ao corpo por meio desse atributo físico que é a voz. Seus significados mantêm a integridade da arte vocal, e podem ser construídos 
na busca de uma experiência diferenciada de linguagem. Uma linguagem que esteja viva no corpo, em que o pensamento seja experienciado no corpo, as emoções tenham existência física. $\mathrm{Na}$ qual, plenas de pensamento e emoções, as ondas sonoras fluam através de um corpo e sejam percebidas, sensorialmente, por outros corpos que experimentem o(s) pensamento/emoções contido(s) nas vibrações do som.

Esse momento supõe competência: saber fazer, saber dizer, saber ser no espaço e na duração - o corpo dando forma ao vazio, a voz dando forma ao silêncio, e o movimento de ambos recriando o tempo.

Corporifica-se então, uma ação vocal que oferece, a quem ouve, uma palavra na qual não há lugar para dúvidas ou indecisões: uma publicação oral não tem rascunho; não permite ao ouvinte qualquer possibilidade de volta - independente do efeito buscado, a comunicação é imediata. É assim que o texto, publicado oralmente, apóia-se sobre um efeito de presentificação instantânea: mesmo que a audição aconteça muito depois de ter sido composto, ela só pode ser imediata.

À medida que o intérprete canta, declama, diz, limitações mais ou menos fortes, decorrentes do momento, geram sua ação. Esta, em qualquer caso, empenha uma totalidade pessoal: o conhecimento, a inteligência, a sensibilidade, os nervos, os músculos, a respiração e o talento para reelaborar tudo isso num espaço de tempo muito breve. O sentido da representação advém dessa unidade, resultado de um procedimento que a orienta e da posse de uma técnica expressiva particular, que é a arte da voz. Desse modo, os valores que emergem da ação vocal estão muito além das determinações lingüísticas e derivam da própria faculdade da linguagem, tornando a vocalidade poética.

Esta palavra poética é intensa, arquivo sonoro das vozes cotidianas; sua finalidade é representar o todo existente, revelando o que há por trás do grande discurso social. Garantindo uma identidade, a transmissão, a tradição, e dando início a transformações, à criação, à diferença, a palavra poética é, ao mesmo tempo, memória e invenção: a palavra que liberta o canto, que dá vida às narrativas, a palavra que significa o teatro.

No teatro, o discurso sempre se estrutura por um artifício que abrange a totalidade de uma situação e põe em jogo uma qualidade própria da voz: em sua função primeira, anterior à influência da escrita, a voz não descreve; ela age e deixa que o gesto indique as circunstâncias. Dada essa amplitude, é em torno do gesto que se organiza a cena inteira, subordinando a palavra. Mas ele, em vez de sufocá-la, vai valorizá-la, enquanto ela explicita seu significado, pois, ao que o olhar registra, falta a espessura concreta da voz, a percepção do sopro, a urgência da respiração; falta a condição de retomar, sempre, o jogo de presentificar um objeto ausente, pelo som da palavra.

O trabalho vocal que se estrutura sobre esse conceito busca a condição que tem uma voz, ao apropriar-se de um texto ou canção, de atualizá-los, por um momento, ao assumir a imediatez e a instantaneidade da "performance" mantendo, ao mesmo tempo, a memória do enunciado e da sonoridade, assegurando o espaço da criação.

O intérprete pode assumir a instantaneidade da "performance" e integrá-la na forma de seu discurso. Isso implica uma capacidade particular de eloqüência, fluência de frase e dicção, poder de sugestão, domínio dos tons e dos ritmos, todo 
um saber técnico, além do conhecimento das formas: a posse de um vocabulário e das regras para sua combinação, numa espécie de gramática poética. Então, mais que de procedimentos literários, a estruturação da palavra poética resulta do discurso; mais que em termos de gramática, as normas se definem em termos de dramaturgia.

A opção por esse percurso vai determinar o papel que, na representação, atribui-se ao desempenho vocal, assumindo que a magia pressupõe a perfeição da técnica e que o acaso tem muito pouco a ver com a arte.

\section{... alguns princípios...}

Interferir na natureza e transformar a matéria faz parte da vocação cultural humana. Presente na arte, por definição, essa tarefa é desempenhada sempre no limite do sagrado e da magia, manipulando a matéria conhecida para dar-lhe outro significado, fazendo com que uma coisa se torne outra, mesmo continuando a ser ela mesma.

Se a matéria é carne, emoções e pensamento, um corpo fabricado pela cultura que o cerca vai recriar a sua própria substância, superar limites e imposições, extrair outras configurações de seu todo, potencializar ao máximo suas funções para elaborar, como um mágico, na perfeição da técnica, a representação. Um corpo que não é uma obviedade física é um devir simbólico no qual se articulam, a cada instante, as imagens dadas pelo meio em que vive e podem se rearticular tantas imagens quantas ele for capaz de imaginar, buscar, observar, exercitar. Vencendo as imposições da gravidade, a parte mais flexível do corpo é livre para transpor e mover-se no espaço. $\mathrm{E}$, no entanto, mantém sua realidade física, constituindo-se em matéria concreta ${ }^{1}$.

Este princípio abre a voz à interferência determinada e consciente em sua construção, como a tela e as tintas se oferecem a um pintor: o suporte material, a substância que permite a manifestação da forma, transformando o abstrato em concreto, tornando visível o invisível, fazendo, do ausente, presença. Assim, uma voz responde mais propriamente à sua função, na representação, quando se desprende dos significados abstratos contidos na palavra para se ligar à concretude da materialidade sonora.

A geração dessa voz está diretamente ligada à identificação e ao reconhecimento de sua corporalidade, e a um redimensionamento físico pela expansão do corpo, essa unidade psicofísica que decididamente se organiza para uma função específica, poética, harmonizando seus movimentos internos e externos, reunindo pensamento, emoção, fisicalidade.

O trabalho vocal que se desenvolve pela adoção e imitação de um modelo, por meio da repetição de formas acabadas, fórmulas prontas, soluções permanentes, é limitado e torna-se limitador, quer seja proposto sobre si mesmo, quer seja na relação com uma linguagem. Percorrer esta via é admitir que uma técnica existe por si mesma, sem depender de um organismo vivo, consciente e dotado de imaginário,

1 O som é resultado de um fenômeno físico que só acontece num meio onde exista matéria, e acontece por meio de uma seqüência periódica de compressão e descompressão dela. Quando um som é produzido, alterações ocorrem no meio. $\mathrm{O}$ mesmo se dá com a voz. A vibração das pregas vocais altera o fluxo de ar que passa por elas, e este meio material, ar, alterado, é o som vocal. Um som, produzido, multiplica a alteração da matéria: uma porção alterada modifica a que lhe está mais próxima, e essa seqüência de alterações, através da matéria, é a propagação do som. 
que adote seus procedimentos e a construa em seu corpo, a seu modo, criando, pela matéria que lhe é própria, a individuação da forma.

A identificação, o reconhecimento e a apreensão física do funcionamento dos mecanismos do corpo levam, mesmo que mais lentamente, a um aprendizado diferenciado: relaciona a estrutura corporal interna à existência e à ocorrência da sensação, da emoção, do movimento e libera uma voz pronta para revelar essas relações. É um percurso que permite organizar o saber para além das formas, incorporando os conteúdos: aquilo que existe em termos de estrutura, função e energia. O que se aprende, então, é estar disponível a um processo constante, pessoal, de elaboração e reelaboração de um repertório técnico individual, ancorado na adoção de procedimentos que se organizam pela apreensão de princípios e fundamentos apoiados na absorção de um conceito sobre a voz, que se estabelece a partir da definição de sua função como elemento integrante da atuação. É a apropriação física de um trajeto que busca a autonomia: um saber que se sedimenta de forma única, pela memória e de coração, que é propriedade privada do artista, uma "tradição de si mesmo", para dispor como quiser.

Uma distinção qualitativa emerge do trabalho com a fisicidade e a percepção corporal: a noção de tridimensionalidade do corpo, por exemplo, torna-o mais envolvido no movimento e otimiza sua capacidade de utilização tridimensional do espaço; ao mesmo tempo, cria-se um estímulo à imaginação e um impulso individualizado para a ação, dotando-a de origem, autoria.

Fica estabelecido, então, que voz é corpo, num corpo vivo em cada uma de suas partes, capacitado a estabelecer relações funcionais entre o espírito, a mente e a matéria. E se a voz é físico, é possível concebê-la como ação, ambas originadas num mesmo impulso de respiração. O som vocal gera sensações e impressões, pela vibração, e as mantêm presentes, em emoção, no movimento. É o princípio da voz como materialização da ação física, permeando da pele ao sistema nervoso, sendo percebida através dos poros e dos ossos, e não apenas pelos ouvidos; esse atributo que estabelece o contato físico entre seres humanos distantes um do outro: a manifestação de uma interioridade livre para invadir outros corpos, provocando respostas fisiológicas internas, profundas.

$\mathrm{Na}$ função poética da voz, é assim que se dá a comunicação: corpo-ar-corpo, que vibra em conjunto, que sofre alterações simultaneamente, e que forma um todo unificado pelo som. Tratada assim, a voz é concreta, um prolongamento físico que, pelo toque, estabelece a comunicação.

A voz, pois, é a coordenação de muitas coisas, a começar de uma coordenação funcional que se dá pela conexão de todo o corpo tecendo seu mecanismo e de todo o ser tramando seu sentido.

Estabelecer a ligação entre a realidade física e todo o simbólico a ser trabalhado e representado por ela é função do imaginário, essa ponte entre a concretude e a abstração.

O som é invisível. A tendência, então, é entender a voz como algo abstrato, sobretudo porque nos chega ligada às palavras e seus significados. Saber como tudo se organiza, fisicamente, para produzir o som vocal, é esclarecedor quanto à sua

\footnotetext{
${ }^{2}$ O termo foi utilizado por Franco Ruffini em Conferência durante o Seminário Internacional "Teatro em fim de milênio". Tradução e transcrição da fala por Ricardo Ponti, Maria Lucia Raimundo e Nair d'Agostini.
} 
concretude e revelador quanto à convivência entre o universo dos símbolos e as determinações da matéria sonora.

Como o mecanismo de produção do som vocal não é aparente, é necessária uma estrutura imaginária para entender o que acontece: um processo mental que combina imagens e sensações, dotando a voz de concretude e plasticidade, disponível à interferência proposital em sua elaboração.

\section{... e outros tantos procedimentos.}

Visualizar a ossatura para construir sua imagem como estrutura de sustentação do corpo é um procedimento que libera a musculatura para os movimentos, desde os mais simples e evidentes até os mais complexos e sutis. Recuperar, alongando, os espaços que a tensão rouba entre as articulações, especialmente entre as vértebras, inicia o redimensionamento corporal que pode ser percebido como sensação nascida de uma alteração física real. O peso do corpo se apóia no chão, direcionando a gravidade, numa dispersão aberta e equilibrada, tendo os pés como raízes que se espalham e se aprofundam para sustentar a pélvis, o sacro e o encaixe das coxas. Esta é uma boa base para o som desenvolver grande extensão, sobretudo se a coluna vertebral estiver realmente aberta, em constante energia ascendente, adaptando-se à troca de peso da respiração, "muscularmente" equilibrada e neurologicamente sensível, pronta para responder. Os músculos livres, em torno do torso, tornam-se sensiveis à percepção do movimento tridimensional do diafragma, na respiração, ampliando o espaço ocupado pelo corpo. Na mesma medida, incrementa-se a capacidade de experimentar sensações e impressões mais sutis a serem incorporadas na construção de uma imagem corporal.

Visualizar a imagem que o próprio corpo recorta no espaço traz a consciência de sua tridimensionalidade, numa percepção para ser explorada e incorporada à memória e ao pensamento físico.

A ossatura, pela resistência de seu material é, ainda, condutora das vibrações do som, através das articulações, aos limites corporais mais distantes do seu ponto inicial, expandindo, amplificando, e projetando o corpo, em sua sonoridade, para além de seus limites.

Quando o corpo, como um todo, se compromete na manifestação da sonoridade, os esforços são divididos por uma área muscular e óssea muito mais extensa, se comparada àquela envolvida na adoção da voz como elemento dotado de existência autônoma.

O som inaugural, produzido por um corpo organizado em sua ossatura e musculatura, tem a amplitude de um suspiro de alívio, e está sujeito à passagem da respiração através das pregas vocais, na garganta, para criar as vibrações que são reconhecidas como uma voz individual. A respiração depende dos pulmões, que se estendem até a metade do dorso. A musculatura da respiração é entretecida em torno da caixa das costelas, continuando por baixo dos pulmões, no diafragma, conectando-se com a coluna vertebral e enraizando-se profundamente na pélvis. Não é metafórico dizer que o corpo respira.

O reconhecimento da respiração deve identificar o movimento que se inicia no centro do diafragma e expande o corpo em seis direções, na inspiração, permi- 
tindo a sensação de tridimensionalidade do tronco que é, então, um invólucro em torno do ar. O movimento inverso, de retorno das seis direções para o centro, na expiração, dá uma primeira noção de apoio, resultado da pressão da musculatura do torso, em torno do ar, para voltar à sua posição inicial.

A coluna vertebral é parte fundamental da respiração. O eixo central da coluna é indispensável para prover a força do movimento para a respiração, nas direções alto e baixo. A pressão negativa do ar, na pélvis, cria uma troca com a parte superior do corpo, no enchimento dos pulmões, dando suporte à respiração. Se a coluna permanecer rígida, se as vértebras perderem sua ação seqüencial, isso vai afetar a respiração e, por conseqüência, a qualidade do som.

Esta respiração consciente integra a representação como um elemento visual e espacial, quando é concebida e utilizada dessa forma ativa, tridimensional. Configurada assim, amplia as possibilidades de significação ao propor a percepção da vida no corpo, revelando como se faz, enquanto faz, como pensamento físico.

A respiração é o início do som vocal, tanto quanto da ação e do movimento, e funde esses esforços num impulso único; voz, ação e movimento terão a amplitude que tiver o impulso interno, inicial, da respiração num corpo sensível para reconhecê-lo e dar-lhe forma.

A opção por somar o corpo ao trabalho sonoro torna a respiração consciente indispensável e faz necessário aprender um modo de respirar que sustente a ação e o som encontrando, no corpo, o impulso que vai criar a coordenação entre os dois.

Trabalhar dessa forma alinha a presença e a abertura estrutural do corpo, que se torna suporte para um som claro e aberto. A qualidade do som reflete o estado do corpo e o que, nele, está vivo. Se houver tensão, o som vai refleti-la. Se o corpo estiver aberto nas articulações, respirando livre e sem tensão na musculatura, a voz vai refletir este estado.

A respiração age sobre a percepção. Cria, no corpo, uma tendência fisicamente mais receptiva, "muscularmente" mais suscetível.

A respiração consciente e a percepção diferenciada do corpo são procedimentos fundamentais para a produção do som vocal na perspectiva de sua fisicidade. É a respiração que determina como se cria o som no corpo porque seu percurso e espaço abrem, antes, o caminho da sensação e da percepção.

É fundamental, para o imaginário, buscar ver além do mecanismo funcional da respiração. Há uma energia respiratória, no corpo, que está além do simples ato de respirar, num nível mais profundo, numa experiência corporal total.

O elo entre a respiração e a energia interna é dado pela sensibilidade e depende dela para o desenvolvimento de uma capacidade de expressão ampliada. Alguns atributos podem ser ligados à voz do ator: extensão, variedade, beleza, clareza, poder, intensidade. Mas é a sensibilidade que valida todos estes atributos, que permanecem nebulosos se não refletirem a extensão das sensações, a variedade do pensamento, a beleza do conteúdo, a clareza da imaginação, o poder das emoções, a intensidade do desejo de se comunicar. Se a comunicação do interior para o exterior pretende ser verdadeira, as energias que abastecem os músculos da voz precisam estar afinadas, com extrema sensibilidade, às energias ainda mais refinadas da criação.

Nessa opção de trabalho vocal, é preciso partir do entendimento de que cada corpo tem seu próprio ritmo e pode encontrar sua própria respiração. O corpo 
pode usar mais de si mesmo do que apenas a superfície muscular.

Nossa primeira relação com o som é através da respiração. Assim, o trabalho com a respiração deve ter improvisação, atividade, estímulos, consciência, sensação física e atenção à percepção.

O corpo quer respirar plena e confortavelmente. A tentativa de se manter dentro de padrões familiares restringe a respiração. Respirar traz vitalidade, que traz sensações, que podem trazer o novo e, às vezes, há a tentativa de evitá-las. O trabalho deve, então, instalar um espaço diferenciado, dedicado à construção de elementos que se destinam a uma finalidade específica, a representação, permitindo a liberdade do corpo para que as sensações aconteçam. Trabalhar estas relações permite e propicia que a respiração se torne multidimensional.

A voz se organiza com a ação do diafragma, num trabalho de coordenação seqüencial entre os músculos abdominais e torácicos, na inspiração e expiração. Esse arranjo se equilibra com o aparato vocal, que permite a saída do ar para a produção do som.

A ação do diafragma, que se contrai ativamente na inspiração, expandindo o corpo, descontrai-se na expiração. Os dois movimentos são coordenados à força da liberação do ar através do laringe e das pregas vocais, resultado da pressão exercida pela musculatura do tronco no retorno à sua posição original. A intensidade do som depende desta relação. Manter a imagem de um centro, do qual parte e para o qual retorna o movimento da respiração e do som, traz o benefício fisiológico do equilíbrio da pressão do ar sobre as pregas vocais, apurando o timbre: ar demais força uma separação sustentada das pregas, provocando sopro. No entanto, equilíbrio não quer dizer contenção. A imagem do suspiro de alívio é proposta exatamente para afastar a idéia de resistência, de restrição.

A cada tom, as pregas vocais vibram - para cima e para baixo e de lado a lado - numa freqüência específica. Um tom alto tem freqüência de vibração mais rápida do que um tom baixo. O tom também depende da espessura das pregas: se grossas - baixo - ou delgadas - alto. A abertura e o fechamento das pregas criam uma fenda no meio do laringe: se ela se alarga, o tom é baixo; se ela se estreita, o tom é alto.

Há mais do corpo envolvido nessa relação de respiração, voz e tom.

O diafragma pode ser considerado apenas nesse trabalho com os músculos abdominais e torácicos na respiração. Há, porém, uma outra imagem que o visualiza como uma camada estendida entre duas regiões de órgãos - a de cima, contendo pulmões, coração, esôfago; e a de baixo, sobre a qual o diafragma descansa, contendo estômago, intestino, rins e fígado. Os órgãos e seu peso têm mobilidade, dentro do tronco, movimentando-se para cima e para baixo com a ação do diafragma. Se os órgãos não estiverem rigidamente tensos, em seus lugares no torso e, sim, mais sensíveis, respondendo à ação do diafragma, ele pode trabalhar de forma mais plena e efetiva. Para isso, contribui o alongamento e a liberação da coluna, articulações e musculatura do tronco, ampliando os espaços internos do corpo e tornando a possibilidade de ressonância do diafragma mais aberta e livre para se expandir por entre os órgãos, incrementando a intensidade do som.

A emissão do som é muscular e sua anatomia ganha contornos nas alterações dos canais por onde fluem livremente suas vibrações, na abertura e posicionamento da boca, nas possibilidades de encontros entre a língua e o palato, no desenho dos lábios, 
ajudando a criar texturas, cores, timbres, em formas que a fonética chama de vogais, cujas características individuais decorrem de uma acomodação dos sons nas cavidades de ressonância do corpo. Tonicidade e plasticidade em toda a musculatura que forma a boca, liberdade de movimentos para os maxilares, na prática, aumentam e refinam a emissão do som em sutilezas na revelação de emoções, impressões e sensações através do som.

O som que emerge de sua fonte profunda, no corpo, projeta-se no espaço como um jorro contínuo, em torno do qual a boca recorta e esculpe formas sonoras. A boca é tridimensional e seu formato e espaço de ressonância conduzem o som para o espaço externo.

A articulação e suas possibilidades de experimentação põem a voz em movimento, estabelecendo a ligação entre os sons numa ação coordenada de resistência e adesão dos lábios, língua, palato, dentes, maxilar, à saída do ar, definindo os ruídos nomeados como consoantes.

Um procedimento muito comum no trabalho vocal utiliza a criação de sons que, escutados, são guias para ajustes feitos sobre sua forma externa, sobre a matéria que já não está mais no corpo, dispersando a integridade do trabalho interno. Mas há uma outra escuta possível, com o corpo, fundamental quando se trabalha, primeiro, a sensação do som. É um ouvir sensível; sentir/ouvir e promover ajustes nas bases internas para alterar os resultados. Apenas escutar e manipular o resultado sonoro é fazer duas coisas separadas, quebrando a unidade que deve presidir o desempenho.

Este trabalho não é para ser realizado com o pensamento crítico, buscando aquilo que soa bem. Ele deve acontecer num nível mais puro, focado, antes de tudo, na expressão do corpo, na sensação do som e na resposta, no corpo, a esta sensação. Esta atitude isenta da obrigação de tentar soar bem antes de estar apto a se expressar com a voz. Há, aí, uma orientação diferenciada, menos avaliadora, que muda a qualidade do som: ele se torna mais pessoal.

O som que, em sua produção, contém um corpo, é mais enraizado nas emoções e soa diferente, tem outra textura. Os tons se tornam mais plenos, mais ricos, com mais harmônicos, que vão caracterizar melhor o som. Caracterizá-lo a partir daquilo que é dado pelas sensações geradas pela vibração, mais do que a partir daquilo que o som parece ou deve ser, inicialmente. A partir daí, o desenvolvimento pode se dar pelo uso do ritmo no corpo, do espaço, das dinâmicas do movimento e seu peso na criação do som. Este é um tipo de orientação particularizada na construção da voz poética.

A associação do movimento físico ao som não supõe uma sincronicidade nem uma imitação. $\mathrm{O}$ corpo não se limita a duplicar o som e o som não fica preso à reiteração do corpo: eles interagem.

Alinhando o impulso, a intenção da fisicalidade com o som, é possível encontrar a fonte comum com o movimento, no corpo. A interação traz algo consigo que revela não serem, ambos, um único elemento. $\mathrm{O}$ impulso criado no corpo não precisa ser sempre sonorizado; nem todos os sons têm de ser refletidos no movimento. Também há silêncio e imobilidade. Corpo e som podem interagir num percurso mais vital e menos previsível.

O potencial do trabalho com movimento - mesmo que em alguns momentos 
este não aconteça - desenvolve a habilidade de imaginar o movimento do corpo no espaço, o que é importante para a produção sonora como ação; se o som existe como um pressuposto, no movimento, a concentração e o movimento serão diferenciados, mesmo que os sons não se concretizem.

Procedimentos ancorados em princípios definidos e conceitos claros abrem a prática a uma experimentação sem restrições: o que deve ser preservado é a concepção que, construída pela experiência de cada um, sustenta a atitude do artista no confronto com os desafios de seu ofício. 


\section{REFERÊNCIAS}

BANU, Georges (Org.). De la parole aux chants. Paris: Actes SUS - Papiers, 1995. (Apprendre, n. 4).

BERRY, Cicely. The actor and the text. London: Virgin Books, 1993.

BERRY, Cicely. Voice and the actor. New York: Macmillan, 1973.

BEUTTENMÜLLER, Maria da Glória; LAPORT, Nelly. Expressão vocal e expressão_corporal. Rio de Janeiro: Forense Universitária, 1974.

BLOCH, Pedro. Falar é viver. Rio de Janeiro: Nórdica, 1980.

BLOCH, Pedro. Você pode falar bem: problemas de comunicação oral. São Paulo: Nacional, 1986.

BRASIL. Ministério da Educação. Normas para a língua falada no teatro. Rio de Janeiro, 1958.

CONGRESSO DA LÍNGUA NACIONAL CANTADA, 1., 1937, São Paulo. Anais... São Paulo: DCPM, 1937.

DUARTE, F. J. C. A fala e o canto no Brasil: dois modelos de emissão vocal. ArteUNESP, São Paulo, n. 10, p. 87-97, 1994.

É PRECISO juntar de novo palavra e corpo. Estado de São Paulo, São Paulo, 30 abr. 1995. Caderno 2.

FERREIRA, Leslie Piccolotto (Org.). Trabalhando a voz. São Paulo: Summus, 1988.

FERREIRA, Leslie Piccolotto (Org.). Voz profissional: o profissional e a voz. Carapicuíba: Pró-Fono Departamento Editorial, 1995.

FERREIRA, Leslie Piccolotto et al. Temas de fonoaudiologia. São Paulo: Loyola, 1984.

FORTUNA, Marlene. A performance da oralidade teatral. São Paulo: Annablume, 2000.

FOUCAULT, Michel. As palavras e as coisas. São Paulo: M. Fontes, 1999. (Coleção tópi$\cos )$.

FRY, Dennis. Homoloquens: o homem como animal falante. Rio de Janeiro: Zahar, 1978.

GAYOTTO, Lucia Helena. Voz partitura da ação. São Paulo: Summus, 1997.

GROTOWSKI, Jerzy. La Voix. Le Théâtre: Cahiers dirigés pour Arrabal, n. 1, p. 87-131, 1971. 
HAROCHE, Claudine. Da palavra ao gesto. Campinas, SP: Papirus, 1998.

LINKLATER, Kristin. Freeing Shakespeare's voice. New York: Theatre Communications Group, 1992.

LINKLATER, Kristin. Freeing the natural voice. New York: Drama Book Publishers, 1976.

MAIA, Eleonora Motta. No reino da fala: a linguagem e seus sons. São Paulo: Ática, 1985.

MAMMI, Lorenzo. João Gilberto e o projeto utópico da bossa nova. Novos Estudos CEBRAP, São Paulo, n. 34, p. 63-70, 1992.

MATOS, Cláudia N. de; MEDEIROS, Fernanda T. de; TRAVASSOS, Elizabeth (Org.). Ao encontro da palavra cantada: poesia, música e voz. Rio de Janeiro: 7 letras, 2001.

MELLO, E. B. de Souza. Educação da voz falada. Rio de Janeiro: Atheneu, 1984.

MURCE, Newton. O ator, a vocalidade poética e uma escritura no corpo. 2002. Monografia (Graduação) - Universidade Estadual de Campinas, Campinas, SP, 2002.

NUNES, Lília. Manual de voz e diç̧ão. Rio de Janeiro: SNT, 1972. (Série Cartilhas de teatro).

PALAVRA tem volume, cor, temperatura e sabor. Estado de São Paulo, São Paulo, 30 abr. 1995. Caderno 2.

ONG, Walter. Oralidade e cultura escrita. Campinas, SP: Papirus. 1998.

ORLANDI, Eni P. As formas do silêncio no movimento dos sentidos. Campinas, SP: Unicamp, 2002. (Coleção Repertórios).

QUINTERO, Eudósia Acuña. Estética da voz: uma voz para o ator. São Paulo: Summus, 1989.

ROUSSEAU, Jean-Jacques. Ensaio sobre a origem das línguas. Campinas, SP: Unicamp, 1998. (Coleção Repertórios).

SALZSTEIN, Sonia. O moderno como problema. Folha de São Paulo, São Paulo, 09 ago. 1997. Jornal de Resenhas, p. 8.

SOARES, R. M. Freire; PICCOLOTTO, Leslie. Técnicas de impostação e comunicação_oral. São Paulo: Loyola, 1977.

VALENTE, Heloísa de A. D. Os cantos da voz. Entre o ruído e o silêncio. São Paulo: Annablume, 1999. 
LA VOZ. Mascara, México, ano 2, n. 4/5, 1991.

ZUMTHOR, Paul. Introduction à la poésie orale. Paris: Édition du Seuil, 1983.

ZUMTHOR, Paul. A letra e a voz. São Paulo: Companhia das Letras, 1993.

ZUMTHOR, Paul. Performance, recepção, leitura. São Paulo: Educ, 2000. 